\title{
Testing a Process-Product Framework for Conceptualizing Motivation
}

\author{
David Palmer \\ School of Education, University of Newcastle, \\ University Drive, Callaghan, NSW, Australia, 2308 \\ Tel: 612-4921-5715 E-mail: david.palmer@ newcastle.edu.au
}

Received: March 17, 2019

doi:10.5296/gjes.v5i1.14514
Accepted: April 16, 2019

Published: April 30, 2019

URL: https://doi.org/10.5296/gjes.v5i1.14514

\begin{abstract}
This study explored the idea that motivation for learning can be a process as well as a product: the product being an active state of motivation whereas the process would include the antecedents that created that state. This hypothesis was tested by interviewing 47 university students immediately after normal lectures. Results showed that $89 \%$ had experienced an active state of motivation (the product phase) that was influenced by antecedents that included personal characteristics (e.g., self-efficacy, individual interest), temporal personal factors (mood, fatigue), and contextual factors (teacher enthusiasm and "interestingness"). It was concluded that process-product is a potentially useful framework for conceptualizing motivation.
\end{abstract}

Keywords: Motivation state, Appraisal, Efficacy, Expectancy, Extrinsic 


\section{Introduction}

Much of the research on motivation has focused on the social cognitive constructs that can influence how students approach learning tasks, and these have usually been studied as relatively stable, personal characteristics, or traits (Cadigan, Yichun, \& Clifton, 2013; Ekahitanond, 2013; Landrum \& Garza, 2016; Pintrich, 2003; Schunk, 2004). Other authors have explored the states of motivation that students might experience when they are active in learning tasks (Culbertson, Fullagar, Simmons, \& Zhu, 2015; Järvenoja, Järvelä, \& Malmberg, 2017; Malmberg, Pakarinen, Vasalampi, \& Nurmi, 2015). However, there is still little consensus about the relationships between traits and states of motivation.

A theoretical framework that might help to inform this issue was originally proposed by authors such as Winne and Marx (1989) and Wolters (2003), who argued that motivation could be regarded as a process and a product. Building on their work, it is hypothesized for the present study that the motivation product is a state representing a student's active desire to learn information that is immediately available; whereas the process includes the antecedent components that were involved in creating that state. In this way, motivation can refer to a student's immediate feeling of being motivated as well as to the processes that created that feeling. It is important to note that this process-product view of motivation is not aligned with the process-product research on teaching, in which the processes are teacher behaviors and the product is student achievement (e.g., Creemers \& Kyriakides, 2015). Instead, the present study uses the terms process and product to refer solely to the antecedents and end state of student motivation.

Although it has received little attention from researchers in recent years, the process-product view of motivation is worthy of study because of its potential to provide a framework for bringing together the existing studies of states of motivation with the studies of social cognitive processes of motivation. One way to test the validity of a process-product framework is to investigate whether a state of motivation (a product) can be derived from antecedent components including trait-like characteristics. This is the purpose of the present study.

\section{Theoretical Framework}

Winne and Marx (1989) originally proposed that motivation is both a process and a product. They argued that motivation is both recursive and simultaneous: recursive because a current state of motivation is influenced by one's prior states of motivation; and simultaneous because it is a process as well as a product. The product is a motivated state of being: "a positive state of motivation is a necessary condition for students to learn from instruction" ( $p$. 225). They proposed that the process accounted for why students participate in classroom tasks, including cognitive operations that assemble pre-existing propositions, such as attitudes and efficacy expectations, with information about the current task. The view of these authors differed to later views because they stopped short of suggesting that the product was a direct result of the process.

Wolters (2003) focused on how students monitor and regulate their motivation, and the 
processes supporting it. He argued that motivation could be characterized as a process and a product: the product being a state encompassing "a student's willingness to engage in and persist at a task" (p. 190), which could be experienced in different ways, including "being interested, feeling self-efficacious, or wanting to master a task" (p. 190). On the other hand, the process component was the cognitive processes that created that motivational end state. This would include "the processes that account for a student being interested, feeling self-efficacious, or wanting to master an activity" (p. 190). Thus Wolters (2003) suggested that episodic experiences of interest and self-efficacy would represent end states, whereas the development of those states from their precursors would be the process of motivation.

Wolters' (2003) view in which there can be different types of motivation end states that correspond to interest or self-efficacy, conflicts with the views of more recent authors. Miele and Scholer (2018) outlined a taxonomy of motivation components and argued that a state of motivation is a desire to engage, which they defined as "the experience of being motivated to engage in a task" (p. 5). Furthermore, they proposed that task value, expectancies of success, self-efficacy, and intrinsic value (personal interest) are "components" of motivation, each of which influences the desire to engage.

Studies of interest processes have provided a parallel view. Schiefele (1999) argued that self-efficacy beliefs, attributional beliefs, personal interest, expectancies, and task value beliefs are relatively stable motivational characteristics (at least within particular sets of circumstances) that should not be confused with states. In his view, these constructs are valenced in particular situations, and these valence cognitions are the immediate antecedents of the motivation state which is the wish or intention to engage in a learning activity. Renninger and Hidi (2016) argued that individual (personal) interest has trait-like properties and can be the antecedent of the psychological state of interest that a person experiences during active engagement. This state is characterized by positive affect and a desire to learn more about the information at hand, and it can also be influenced by factors such as expectancies of success, performance goals, and value beliefs (Tanaka \& Murayama, 2014).

In summary, several previous authors have analyzed motivation as comprising an end state as well as a process involving the effects of trait-like beliefs and dispositions as well as task features. Some of the general characteristics of states and traits are summarized below.

\subsection{Characteristics of Motivation States}

Motivation states have been studied from perspectives such as flow (Culbertson et al., 2015), curiosity states (Grossnickle, 2016), emotions (Turner \& Patrick, 2008), and situational interest (Renninger \& Hidi, 2016). States are conceptualized as being episodes in which a particular feeling tends to dominate one's consciousness. In educational settings, states can be dynamic because they can sometimes change in response to changes in teaching techniques or topics within a single lesson (Vollmeyer \& Rheinberg, 2006). However, they can also remain relatively unchanged throughout a lesson if the circumstances support sustained engagement (Ainley, 2006; Kim \& Schallert, 2014; Yanguas, 2011).

Motivation states for learning are typically multifaceted, comprising affective and cognitive 
dimensions. The affective dimension typically involves pleasurable emotions such as liking and enjoyment (Culbertson et al., 2015; Grossnickle, 2016; Tanaka \& Murayama, 2014). The cognitive dimension has been represented as an impetus to become more proficient (Culbertson et al., 2015), a desire to learn (Miele \& Scholer, 2018), an impetus to find out more (Ainley, 2006), or a desire for knowledge (Grossnickle, 2016). The cognitive and affective dimensions are separable because a desire to obtain knowledge (the cognitive dimension) is not the same as the pleasure of achieving knowledge (the affective dimension; see Ortony \& Turner, 1990). Miele and Scholer (2018) pointed out that the cognitive desire to learn is not always positive, because when negative factors (such as fatigue) are experienced it can become valenced from a positive desire to learn through to a negative desire of wanting to disengage.

A final characteristic of motivation states is that they are typically associated with focused attention and concentration. Vollmeyer and Rheinberg (2006) argued that the direct effect of the initial motivation state (i.e., that experienced at the beginning of a learning episode) is the level of concentration when students begin work on the learning material. Other authors have noted that focusing attention and concentration seem to go hand in hand with positive motivation states such as curiosity (Grossnickle, 2016), flow (Culbertson et al., 2015), and situational interest (Renninger \& Hidi, 2016). This is a very important point because focusing attention and concentration are essential learning behaviors, since learning cannot occur if one is not focusing attention on the source of information (Anderman, Noar, Zimmerman, \& Donohew, 2004).

\subsection{Motivation Processes}

Schiefele (1999) and Miele and Scholer (2018) argued that the antecedents of the motivation state would include one's relatively enduring personal characteristics and the way in which they relate to the task at hand. These could include factors such as self-efficacy (i.e., self-judgements about one's ability to perform in a challenging situation; Bandura, 1997), expectancy beliefs (perceptions of one's ability to succeed; Wigfield \& Eccles, 2000), utility beliefs (perceptions of how well a task fits one's future plans; Wigfield \& Eccles, 2000), intrinsic motivation orientation (doing things because they are inherently satisfying; Ryan \& Deci, 2000), extrinsic motivation orientation (the extent to which external incentives are internalized by the individual; Ryan \& Deci, 2000), and individual interest (one's preferences for particular topics or activities; Renninger, Ewen, \& Lasher, 2002).

However, relatively little attention has focused on the extent to which these personal characteristics might be antecedents of a motivation state. Yet the small number of studies that have investigated this issue have generally supported the relationship. For example, Renninger and Hidi (2016) reported that individual interest can influence the state of situational interest, and Tanaka and Murayama (2014) reported that utility value and expectancies of success could influence situational interest. In addition, Litman (2005) argued that intrinsic reward can influence the curiosity state; Malmberg et al. (2015) reported that the extent to which one internalizes extrinsic incentives can influence situation-specific motivation; and Busch, Hofer, Chasiotis, and Campos (2013) reported that perceived ability 
to master a task (which implies self-efficacy) can influence the flow state. Thus, these studies have suggested that a relatively stable belief or disposition can exert an influence on a state of motivation. However, individual students do not hold just one belief in isolation, but rather they have a constellation of beliefs (Snyder \& Linnenbrink-Garcia, 2013) that are influenced by each other (Zusho, 2017). Ainley (2006) further asserted that the way in which these factors interact is also influenced by the nature of the task at hand: "Students come to the task with a range of goals and it is through interaction of these goals with task demands that specific on-task feeling states are triggered" (pp. 397-398). This suggests that it is necessary to consider the simultaneous effects of a wide range of personal beliefs and dispositions.

Contextual factors can also exert an influence on a motivation state. For example, Kim and Schallert (2014) reported that teacher enthusiasm influenced situational interest. Other authors have reported the effects of "interestingness" (which is generated by collative variables such as novelty and humor) on states of curiosity and interest (Grossnickle, 2016; Rotgans \& Schmidt, 2017; Tsai, Kunter, Lüdtke, Trautwein, \& Ryan, 2008). In addition, temporal personal factors should also be considered: Linnenbrink and Pintrich (2002) reported that current mood could influence student perceptions of the classroom situation, and Menna-Barreto and Wey (2008) reported that fatigue can influence student motivation for classroom tasks.

Thus, on the basis that they are antecedents of motivation states, one's relatively stable personal characteristics as well as contextual factors and temporal personal factors can be hypothesized to be components of the process phase. However, a further question concerns the nature of the processes involved. If there are multiple components that can simultaneously exert an influence on the state of motivation it follows that there must be a process of synthesizing their multiple effects in order to arrive at the state of motivation that will be experienced at that particular time and place. The integrated processing of multiple component systems has been referred to as appraisal. According to Op't Eynde and Turner (2006), the appraisal process "involves complex cognitive processing such as decoding current contextual input and comparing the information with personal expectations and goals" (p. 364). Other authors have noted that the factors being appraised can be arranged in a hierarchy in which distal factors exert an influence on proximal factors (Zusho, 2017). Patrick, Ryan, and Kaplan (2007) for example, reported that teacher and peer support were background factors that affected student self-efficacy. In this way, the appraisal process would include the processes of interaction between different antecedents as well as the synthesis of their overall effects.

\section{The Present Study}

The studies above have suggested that a process-product framework might have the potential to bring together the existing research on motivation states together with the relatively trait-like beliefs and dispositions that have been found to influence one's motivation. The present study is designed to test a composite model in which the product phase is hypothesized to be a state in which one experiences an active desire to learn information that is immediately available. This phase may or may not be valenced from positive (a desire to 
learn) to negative (a desire to not learn). On the other hand, the components of the process phase are hypothesized to be the antecedents of that state, and these would comprise one's personal characteristics and how they simultaneously relate to the situation and the learning task.

The purpose of this study was to test these hypotheses in authentic learning environments at tertiary level. The research questions were,

1). Do tertiary students experience an active state of wanting to learn (i.e., the product phase) during their regular lectures and if so, what are its characteristics?

2). Do the antecedents of this state (i.e., comprising the process phase) include the effects of multiple factors operating simultaneously?

\section{Method}

A cross-section, field study design was used. Participants were 47 university students who were interviewed from a wide range of courses. This relatively large number of interviewees was used to allow some quantitative comparison of response patterns. In this way, the study used a combination of qualitative and quantitative methods.

\subsection{Participants}

The participants were undergraduate students typically aged 18-25 at a university in south-eastern Australia. The gender ratio was 38\% females and $62 \%$ males, as these were the proportions who volunteered to be interviewed. The sample was designed to include a wide range of courses in order to identify general patterns that were not restricted to one particular context: It included students from human bioscience (19\%), mathematics (17\%), accounting $(11 \%)$, fine arts $(11 \%)$, chemistry $(11 \%)$, sociology $(9 \%)$, nursing $(9 \%)$, education $(6 \%)$, speech pathology (4\%), and engineering (3\%).

Participants were recruited in the following way. At the end of a regular lecture as the students were packing up and preparing to leave, the interviewer personally made an announcement that any student who was willing to be interviewed about "motivation" should make contact there and then. If a student did volunteer then the interview was carried out immediately in a quiet location just outside the lecture theatre (sometimes more than one student volunteered, but only the first volunteer was interviewed on each occasion).

The rationale for this approach was that restricting recruitment and data collection to the end of the lecture had the advantage of ensuring there would be no interference with each student's natural flow of thoughts and feelings at the time of the lecture (see Tanaka \& Muramaya, 2014). This would ensure that the learning environment was authentic because it would avoid the validity issues that occur when student learning experiences are interrupted to gather data (Loukomies, Juuti, \& Lavonen, 2015). This was an important issue for the present study because a substantial amount of information needed to be gathered from each student, including information about processes and products, and this would have substantially interrupted their attention to the lecture, which would not have been ethically acceptable. 


\section{Macrothink}

Global Journal of Educational Studies

ISSN 2377-3936 2019, Vol. 5, No. 1

These students self-selected for participation, which raises the question of whether they were the ones who were more motivated. However, as will be shown below, the results indicated a wide range of responses. Although most responses suggested positive motivation states, this might be expected at university because students are free to choose courses that interest them.

\subsection{Interview Guide Questions}

One of the aims of this study was to investigate whether multiple antecedents might simultaneously exert their influence on a motivation state. Thus, it was necessary to identify one particular moment in each lecture, and to investigate the motivation state and its antecedents operating at that moment in time. To this end, it was decided to focus all the interview questions on the initial state of motivation (Vollmeyer \& Rheinberg, 2006) that students might experience close to the start of the lecture, and to identify the antecedents operating at that time.

Each student was interviewed once, and the interview lasted about 20 minutes. The interview guide questions had been developed from pilot interviews with five students who were not included in the data set. The same interviewer was used throughout.

- Question 1. At the beginning of the interview, students were shown the wanting-to-learn scale (Figure 1) and were asked Question 1a (Early in that lecture, did you experience a feeling of wanting to learn or not wanting to learn? If so, please mark it on the scale.) and Question $1 \mathrm{~b}$ (Please describe that feeling.). The purpose of this question was to measure and describe the initial state of motivation (i.e., the product phase).

- Question 2. When did that feeling start? The purpose of this question was to confirm the initial state of motivation as that which first occurred close to the beginning of the lecture. In addition, it was necessary to establish that this was an active feeling (a state) rather than the continuation of an ongoing predisposition (a trait), so it was necessary to identify when it had started.

- Question 3. How well were you concentrating at that time, early in the lecture? This question was included to help triangulate the motivation state, since previous research has suggested that positive states of motivation are accompanied by high attention and concentration.

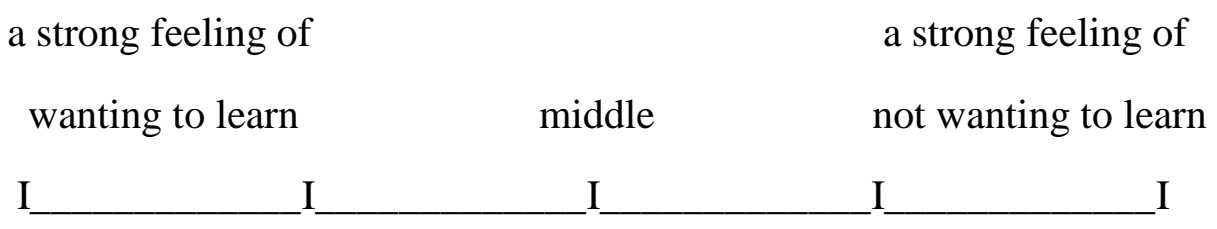

Figure 1. The wanting-to-learn scale

Triangulation was used to enhance the validity and reliability of the qualitative data. 
Triangulation can be carried out in several ways, but it essentially refers to the comparison of different types of data. Long and Johnson (2000) reported that, within a single interview, the interviewer can enhance stability and equivalence by checking that a respondent's answers to different questions are concordant. Thus, Questions 1, 2, and 3 were intended to triangulate the three main characteristics of the motivation state (Aim 1): a desire to learn (Question 1), that was an episodic state rather than an ongoing trait (Question 2), and that was closely associated with focused concentration (Question 3).

Triangulation of the antecedents comprising the process phase (Aim 2) was carried out by comparing concurrence between Questions 4, 5, and 6 (below). These questions focused on Table 1, which was a list of 10 items. Items 1-6 represented personal characteristics and their relationship to the task at hand, but everyday wording was used in preference to technical terms in order to aid participant comprehension. Item 1 (whether you felt confident in this topic) was included because of its close relationship to self-efficacy (Bandura, 1997, stated that confidence relates more closely to self-efficacy when it specifies what the capability is about). Item 2 (whether you expected to really understand the lecture) was included to represent an expectancy belief, and Item 3 (whether your goals for the future related to this topic) was included to represent a utility value belief (Wigfield \& Eccles, 2000). Item 4 (whether you expected to get a warm feeling of achievement in this lecture) was included to represent an intrinsic motivation orientation, and Item 5 (whether you wanted to get a good grade or avoid failing this subject) was included to represent an extrinsic motivation orientation (Ryan \& Deci, 2000). Item 6 (whether you had a personal interest in this topic) was included to represent individual interest (Renninger \& Hidi, 2016; Schiefele, 1999). Temporal factors such as mood and fatigue were represented by Item 7 (whether you were in a good mood) and Item 8 (whether you were tired). Contextual factors such as instructor enthusiasm and interestingness were represented by Item 9 (whether your instructor would be enthusiastic) and Item 10 (whether you expected some interesting things to happen during the lecture). The interview format allowed participants to ask questions and discuss in order to clarify meaning.

- Question 4. Students were shown Table 1 and were asked, Did any of these influence your feeling of wanting to learn at that time, early in the lecture? The purpose of this question was to identify simultaneous antecedents of the motivation state.

- Question 5. Please indicate whether [each item that you identified as an antecedent] had a Major influence, a Moderate influence, or a Minor influence on your feeling of wanting to learn at that time, early in the lecture. The purpose of this question was to investigate whether there was a hierarchy of antecedents.

- Question 6. Please explain how each of your Major factor(s) had influenced your feeling of wanting to learn. The purpose of this question was to provide examples of causative thinking about the relationship. This question focused on the Major factors because they would presumably be the most salient. 
Table 1. List of items from which students could identify antecedents

\begin{tabular}{|l|}
\hline ITEM \\
\hline 1. whether you felt confident in this topic \\
\hline 2. whether you expected to really understand the lecture \\
\hline 3. whether your goals for the future related to this topic \\
\hline 4. whether you expected to get a warm feeling of achievement in this lecture \\
\hline 5. whether you wanted to get a good grade or avoid failing this subject \\
\hline 6. whether you had a personal interest in this topic \\
\hline 7. whether you were in a good mood \\
\hline 8. whether you were tired \\
\hline 9. whether your instructor would be enthusiastic \\
\hline 10. whether you expected some interesting things to happen during the lecture \\
\hline
\end{tabular}

Note. The items were not numbered in the version shown to participants. The items were mixed and regularly changed during the study in order to reduce any effect of the order of the items.

\subsection{Data Analysis}

Inductive thematic analysis (Braun \& Clarke, 2006), involving the coding of response segments that seemed to express the same idea, were used to categorize the students' verbal responses. This was aided by the extensive use of probing and clarifying questions that had been used throughout the interview. To determine inter-rater reliability, two coders independently categorized a representative sample of 36 response segments and agreement was found in $89 \%$ of cases.

The data for the quantitative analyses included the positions of the students' marks on the wanting-to-learn scale (Figure 1). The position of each mark was measured in millimeters from the right hand end of the line, so higher scores represented a more positive level of wanting to learn and the maximum positive score was 100. Other quantitative analyses used numerical scores that were allotted for different categories of response as explained in each section of the results.

Person-centered analysis (Snyder \& Linnenbrink-Garcia, 2013) was used to identify the main types of profiles displayed by individuals.

\section{Results}

Although each interview started with Question 1 (identifying the feeling of wanting to learn) it is necessary to first refer to the Question 2 responses, because some participants needed to be excluded from further analysis as explained below.

\subsection{Onset of the Initial Motivation State (Question 2)}

In response to Question 2 (When did that feeling start?), 91\% of students reported that the feeling of wanting to learn (or neutral/negative forms, as explained below) had started very close to the beginning of the lecture, so this was interpreted as an initial state of motivation 


\section{Ml Macrothink}

Global Journal of Educational Studies

ISSN 2377-3936

2019, Vol. 5, No. 1

(e.g., "When she put the first slide up. I thought, 'I really want to know this"”; female, speech pathology).

However, the other four students $(9 \%)$ gave responses that did not clearly indicate that a state had occurred (for example, one student reported that the feeling had started when she had first enrolled in the course). As it was unclear whether these students had experienced a motivation state they were dropped from further analysis, so only the remaining 43 students will be considered below.

\subsection{Measurements and Descriptions of the Motivation State (Questions 1 a and $1 \mathrm{~b}$ )}

Measurement of each student's mark on the wanting-to-learn scale (Figure 1) revealed a mean and standard deviation (SD) of 77.83 (21.68) indicating that most students were in the positive range of wanting to learn. Figure 2 shows that a majority of students indicated highly positive levels of wanting to learn (100-80 in Figure 2). Many other students indicated moderately positive levels (79-60). A t-test for independent means found no differences between males and females, $t(42)=0.9832, p=.3313$.

Their verbal descriptions (Question 1b) confirmed that $81 \%$ of the 43 students had experienced a positive feeling of wanting to learn, early in the lecture. For example, "I really wanted to learn and understand the new knowledge" (male, accounting) and "Interest in the subject. A feeling of wanting to be here and wanting to learn" (female, visual art). Other responses $(14 \%)$ were coded as neutral, because they suggested indifference. For example, "I didn't think about whether I was enjoying it or feeling. I just felt that I was going through the process" (female, social science). Finally, negative responses (5\%) were coded when students reported they had experienced a feeling of not wanting to learn, early in the lecture. For example, "When I sat down and got out my books and then she started talking about it, and I thought, 'No, I really don't want to be learning this stuff'" (male, mathematics).

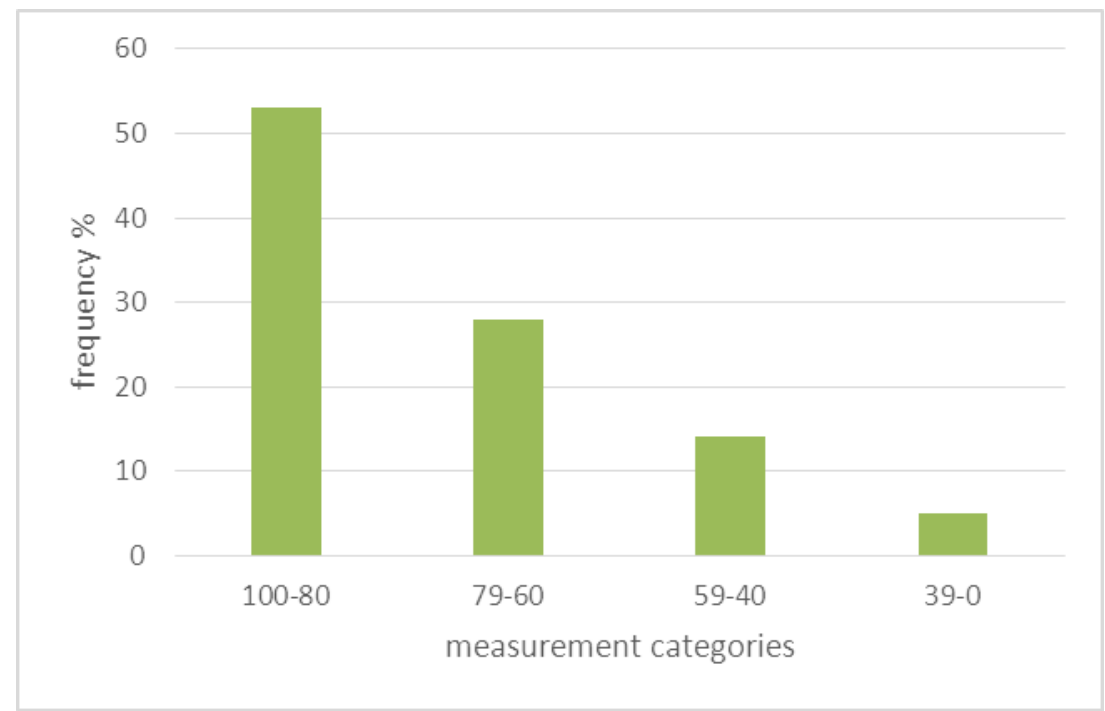

Figure 2. Measurement of wanting to learn $(\mathrm{N}=43)$

Note. $100-80=$ strong level of wanting to learn, $39-0=$ strong level of not wanting to learn. 
To check for concurrence between the students' verbal responses and their marks on the wanting-to-learn scale, each verbal response was allocated a score of either 3 (positive), 2 (neutral), or 1 (negative) and a correlation test was used to compare them to the Question 1a measurements. A highly positive correlation was found, $r(42)=.8859, \mathrm{p}<.000$, indicating that positive verbal descriptions went with scores above 50, neutral verbal descriptions went with middle scores (around 50), and negative verbal descriptions went with scores less than 50 on the wanting-to-learn scale. This suggested that the motivation state could be valenced from positive through neutral to negative, and that all 43 students had experienced one of these forms early in the lecture.

Importantly, the neutral and negative states should not be interpreted as ongoing predispositions towards learning. For example, both of the students who reported a feeling of not wanting to learn stated that they did intend to learn the material at a later time at home:

I knew I would have to go back and study it at some point. It's more appealing to me to do it at home, studying from the textbooks, than it is to listen to the lecture right now. (male, nursing)

\subsection{Levels of Concentration (Question 3)}

Responses to this question (How well were you concentrating at that time, early in the lecture?) were categorized as either high, moderate, or low levels of concentration. For example, "I'd say very well" (high), "Yes, a little bit. Not strongly" (moderate), and "At the start of the lecture I wasn't. I was a bit distracted by stuff on my phone" (low). For analysis, high, moderate, and low levels of concentration were scored as 3, 2, and 1, respectively. A correlation test was used to determine whether these levels of concentration were related to each student's level of wanting to learn, which had been coded as either 3 (positive), 2 (neutral), or 1 (negative). A moderate, positive correlation was found, $r(42)=.5925, p<.000$, indicating that high concentration tended to go with positive levels of wanting to learn.

Thus, these data triangulated well with the data from Questions 1 and 2 in suggesting that students had experienced states of motivation that were valenced from positive through neutral to negative, and that these were positively correlated with levels of concentration. On this evidence, the 43 students in this group were deemed to have experienced an initial motivation state that had occurred close to the beginning of the lecture. This suggested that a product phase had occurred.

\subsection{Antecedents of the Motivation State (Question 4)}

Of the 10 items listed in Table 1, students identified a mean (SD) of 8.23 (1.13) as influencing the motivation state close to the beginning of the lecture. Figure 3 shows that every student identified at least 7 antecedents. This suggests that the initial motivation state was the product of multiple antecedents operating simultaneously.

Each of the 43 participants had included a combination of personal characteristics (Items 1-6) and temporal/contextual factors (Items 7-10) among the antecedents. Figure 3 shows that both groups of antecedents were well-represented. This indicated that the antecedents of the 


\section{Macrothink}

Global Journal of Educational Studies

ISSN 2377-3936

2019, Vol. 5, No. 1

motivation state comprised a combination of personal characteristics and temporal/contextual factors.

The frequency with which each item was chosen as an antecedent is shown in the line graph in Figure 4. Those chosen relatively frequently included Item 6 (personal interest), Item 1 (confidence), Item 2 (expecting to understand), and Item 5 (grades), whereas the items chosen infrequently were Item 8 (fatigue), Item 4 (warm feeling of achievement), and Item 10 (interestingness).

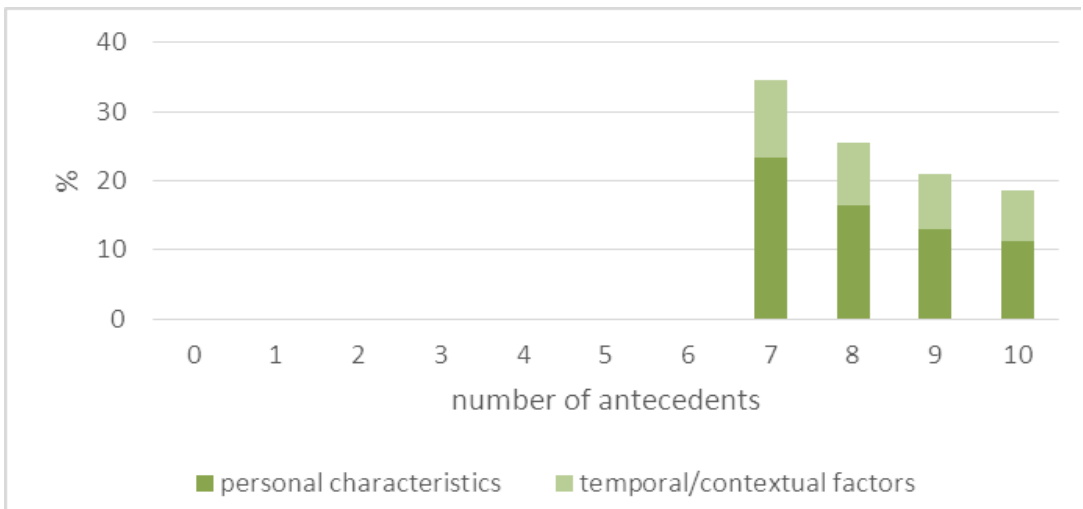

Figure 3. Number of antecedents influencing the motivation state $(\mathrm{N}=43)$

\subsection{Levels of Influence of the Antecedents (Question 5)}

Each of the 43 students indicated that some antecedents they had chosen had been more influential than others. On average, students identified 1.7 Major, 3.7 Moderate, and 2.7 Minor antecedents. This implied that for each individual there was a hierarchy of antecedents.

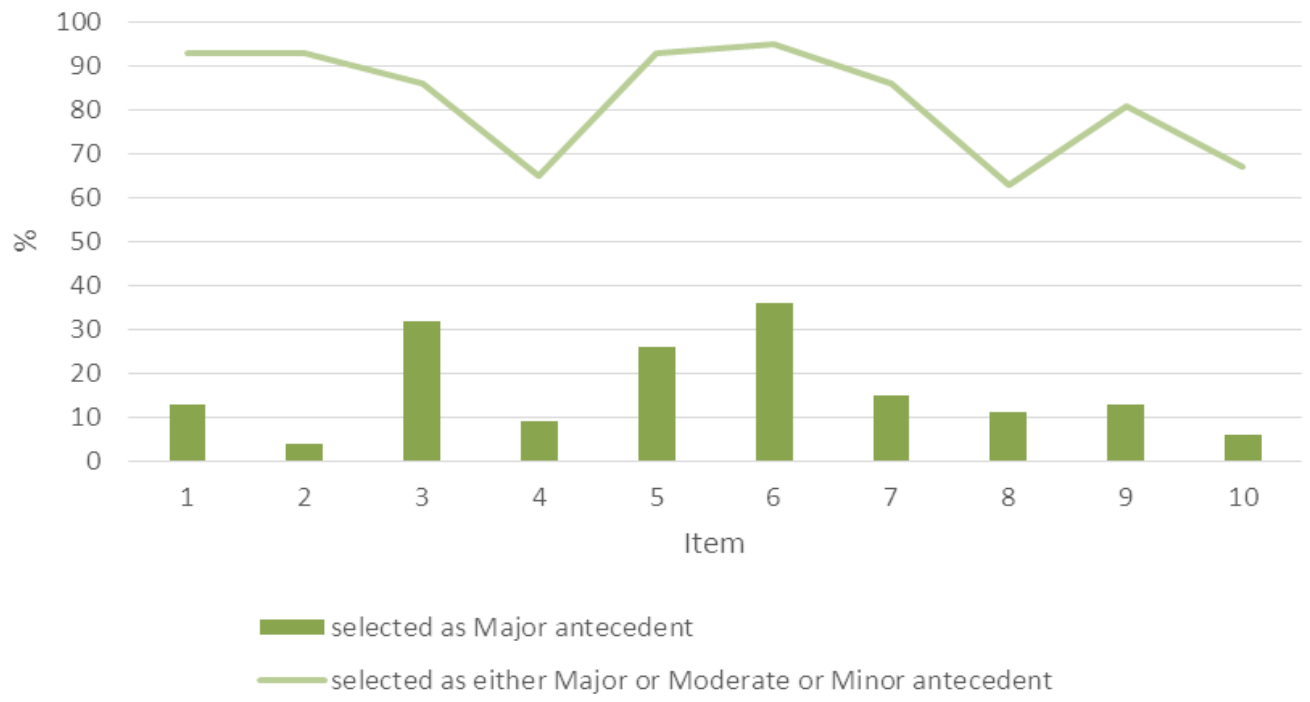

Figure 4. Proportion of students selecting each item as an antecedent $(\mathrm{N}=43)$

Note. Item numbers are: $1=$ confidence, $2=$ expecting to understand, $3=$ future goals, $4=$ warm feeling of achievement, $5=$ grades, $6=$ personal interest, $7=\operatorname{mood}, 8=$ fatigue, $9=$ instructor enthusiasm, and $10=$ interestingness. 


\section{Ml Macrothink}

Global Journal of Educational Studies

ISSN 2377-3936 2019, Vol. 5, No. 1

The Major antecedents were the ones that students indicated had the most influence on the motivation state. The bar graph portion of Figure 4 shows the frequency with which each item was identified as a Major antecedent. It shows that Item 6 (personal interest), Item 3 (goals for the future), and Item 5 (grades) were frequently selected as Major antecedents. However, each of the other items were selected as a Major antecedent by one or more participants, which suggests that every item on the list could potentially be a Major antecedent, depending on the individual.

The most striking finding from Question 5 was the high level of individual variation, which made it impossible to identify substantial profiles. Individual variation was exemplified in two ways: (1) every student in this study had a unique arrangement of Major, Moderate, and Minor antecedents; and (2) even when only the Major antecedents were considered it was found that the majority (67\%) of participants had made a unique choice (for example, only one student selected Items 1 and 5, only one student selected Item 7 only, and only one student selected Items 5 and 6 as Major antecedents, and so on). Thus, there were marked individual variations in the exact items or combinations of items that were chosen.

\subsection{Statements Indicating a Perceived Causal Relationship (Question 6)}

Responses to this question (Please explain how each of your Major factor(s) had influenced your feeling of wanting to learn) indicated that students had perceived a causal relationship between antecedents and the feeling of wanting to learn (Table 2). Overall, 42 of the 43 students provided statements of this type, but the responses of one student were inconclusive.

Thus, the results for this question triangulated well with the findings of Questions 4 and 5 in providing further evidence that all the items in Table 1 were potential antecedents of the motivation state, with the proviso that not all items applied to every student.

Table 2. Examples of causative statements about the antecedents

ITEM 1 (confidence)

You're good at it, so you know you can learn more, so you want to [learn more]. (male, chemistry)

ITEM 2 (expecting to understand)

If I go in thinking I'm not going to understand anything I get distracted or I "zone out". But if I think I can learn this I do want to [learn] because I know I can. (male, mathematics)

ITEM 3 (future goals)

I want to be a science teacher. It makes me want to learn more because that's where I want to get to. (male, teacher education)

ITEM 4 (warm feeling of achievement)

It's just intrinsic satisfaction. If I do it and I know I can do it then I feel good. It makes me want 
to build on that knowledge. Try to learn more about it. (male, accounting)

ITEM 5 (grades)

I want to learn this stuff so I can get a good grade. (male, engineering)

ITEM 6 (personal interest)

If I've got a personal interest in the topic it makes it easier to learn and makes me hungry for that information. (male, mathematics)

ITEM 7 (mood)

I was in a good mood. I was open. When you are in a good mood you open yourself up to learning and to listening. (female, chemistry)

ITEM 8 (fatigue)

I was a bit tired. The tired took away from the wanting to learn. (male, education)

ITEM 9 (instructor enthusiasm)

If [the instructor] is enthusiastic then you tend to mirror their mood, so it brings you up to their level. (male, mathematics)

ITEM 10 (interestingness)

I did expect interesting things to happen in the lecture. The more interesting it is the more I'm able to be captured by the knowledge ... I want to learn further. (female, education)

Note. Italics have been added to indicate a desire to learn.

\section{Discussion}

This study aimed to test a process-product view of motivation. Identification of the product phase was carried out by triangulating three types of information about the motivation state (Interview Questions 1, 2, and 3), whereas identification of the process phase was carried out by triangulating three types of information about the antecedents (Questions 4, 5, and 6). From the original sample of 47 students $42(89 \%)$ did meet each of these requirements, which suggests the process-product pattern had good validity and was prevalent in the population.

\subsection{Characteristics of the Product Phase (Aim 1)}

The students did experience a state of motivation for learning, which was operationalized as a feeling of wanting to learn. This state had valence: The positive range was represented by an active feeling of wanting to learn, and this feeling varied in intensity from moderately positive to highly positive (Question 1a). The negative range was represented by an active feeling of not wanting to learn, which could also vary in intensity. Previous authors have noted that motivation states can be valenced from positive to negative (Miele \& Scholer, 2018). However, comparison of Questions 1a and 1b suggested that midway between the positive and negative ranges there was also a neutral zone characterized by indifference about 
learning.

Although some students experienced neutral or negative feelings about learning, these should be interpreted as states rather than traits because they started close to the start of the lecture (Question 2). Furthermore, these students typically stated that they did intend to learn the content at a later time at home (Question 1). In this way, the neutral and negative motivation states should not be interpreted as representing these students' normal approaches to their studies. Much of the previous literature on motivation has focused on traits rather than states (see Grossnickle, 2016). Yet there are important distinctions between them. For example, a university history student could have a relatively stable predisposition to want to learn about history, but there might be particular occasions during the history course in which he/she might experience temporal factors such as fatigue, which could contribute to an immediate feeling of not wanting to learn at that particular time. This episodic state of mind would therefore not represent his/her normal approach to studies in history, but if it happened on a regular basis then it could have significant educational impact.

The motivation state is educationally important because it positively correlated with levels of concentration: Highly positive levels of wanting to learn went with high levels of concentration, whereas neutral or negative valences went with lower concentration (Question 3). This finding is meaningful because focused attention and concentration are essential learning behaviors: Learning cannot occur if one is not focusing on the source of information (Anderman et al., 2004). One issue however, was that the correlation was only moderately positive (Question 3). This was unexpected because authors such as Winne and Marx (1989) argued that the current state of motivation is the phenomenon that directly determines the focusing of concentration. Consequently, one would expect a highly positive correlation rather than moderately positive. This anomaly may be due to self-regulation (i.e., strategically controlling one's cognitive processes; e.g., Järvenoja et al., 2017), because several students in the present study indicated they were self-regulating their concentration despite low levels of wanting to learn: One reported, "Positive affirmations to stay focused. [Interviewer: You were trying to force yourself to stay focused?] Yes, enough to follow what she was saying. I think it comes with a bit of discipline" (female, mathematics). These instances of self-regulation may have weakened the correlation between the motivation state and the level of concentration.

\subsection{Characteristics of the Process Phase}

According to a process-product view, the process phase would comprise the antecedent factors and their interactions involved in creating the motivation state. Questions 4, 5, and 6 provided evidence that personal characteristics and their relationship to the task at hand (confidence in the topic [representing self-efficacy], expecting to understand [representing an expectancy of success], relevance to future goals [representing utility value], a warm feeling of achievement [representing intrinsic motivation orientation], grades [representing extrinsic motivation orientation], and personal interest [individual interest] as well as temporal/contextual factors such as mood, fatigue, instructor enthusiasm, and interestingness (collative variables) were antecedents of the motivation state. Each student indicated that at least seven of these factors had influenced the motivation state, and evidence from Question 4 
indicated that these antecedents exerted their combined effects simultaneously. This suggests that an appraisal process would be necessary in order to produce a systematic outcome from this complex set of antecedents. Appraisal is usually understood as a process involving the integrated processing of multiple component systems (Op 't Eynde \& Turner, 2006). In this way, the process phase can be inferred to entail a process of appraisal which synthesizes the overall effect of multiple antecedents operating simultaneously.

This study was not intended to investigate exactly how the appraisal process might occur. However, data from Question 5 revealed that some antecedents had more influence than others. Students reported Major, Moderate, and Minor antecedents that varied according to how much influence they had on the feeling of wanting to learn. This structure can be interpreted as a hierarchy in which the Major antecedents would be the most salient. Hierarchies are not necessarily comprised of static layers, but instead the distal factors may actively exert an influence on the proximal factors. For example, Patrick et al. (2007) reported that environmental factors such as teacher and peer support affected student self-efficacy, which in turn influenced task-related interaction. This suggests that the appraisal process could focus mainly on a small number of highly salient factors, and this would, at least to some extent, include the effects of the less salient antecedents.

The most frequently selected Major antecedents (Question 5) were individual interest, utility value (in the form of future goals), and extrinsic motivation orientation (in the form of grades). In each case however, these were selected by only a minority of students (Figure 3). Rather, responses from Question 5 showed that each student's hierarchy of antecedents was highly individualistic: There was very little commonality between individuals in terms of which factors were identified as antecedents and the level of influence of each one. In previous studies of appraisal processes it has been found that when only one or two antecedents are considered then it is possible to create profiles that represent groups of individuals who have responded in a similar way (e.g., Silvia, Henson, \& Templin, 2009), yet the present study has suggested that when the number of antecedents is expanded it is difficult to identify any profile that is common in the population.

The most interesting finding however, was that despite the highly individualistic nature of the process phase it always resulted in a singular product phase, which was the valenced feeling of wanting to learn. This implies that this motivation end state, which was the desire to immediately engage in learning, can be derived from a variety of different antecedent processes in different individuals. Previous authors (Miele \& Scholer, 2018) have argued the case for a single motivation state which is the valenced desire to engage or disengage in a learning activity. While the present study does not preclude that other types of motivation states are possible, it has revealed a little more about how this particular state might be generated.

\section{Conclusions, Limitations, and Implications}

The findings of this study have provided evidence that motivation can be considered a process as well as a product. The product phase was an initial motivation state realized as an active feeling of wanting to learn the information that would be coming up in the lecture. 


\section{$\triangle$ Macrothink}

Global Journal of Educational Studies

ISSN 2377-3936

2019, Vol. 5, No. 1

This state of mind was valenced from positive, through neutral (indifference about learning), to negative (an active feeling of not wanting to learn). These motivation valences were educationally important because they aligned with levels of concentration at that time.

The process phase included the antecedent components and processes that created the motivation state. It was consistently found that the singular motivation state of (valenced) wanting to learn was derived from the simultaneous effects of multiple antecedents. These included relatively stable personal characteristics and their relationship to the task at hand, as well as temporal personal factors, and contextual factors. These antecedents were arranged in a hierarchy that was highly individualistic.

The study had the following limitations. First, the participants only included tertiary students, so the same findings might not necessarily apply to elementary and secondary students who are still in the compulsory stages of education and do not have the same freedom to choose their courses of study. Second, the study only included a limited set of 10 potential antecedents (Table 1) in order to keep each interview within a manageable time frame, but it should not be assumed that these were the only antecedents of the motivation state because other factors such as such as age, ethnicity, prior knowledge, and beliefs about learning were not included.

The main implication for future research is that the process-product perspective might provide a potentially useful avenue for motivation researchers to explore. The present study was set in an authentic educational setting, and student reports of their motivation experiences at that time were able to be comfortably accommodated within a process-product perspective. Thus, it has the potential to bring together diverse strands of research on motivation traits and motivation states. Further research might reveal more about whether or how constructs such as situational interest, curiosity, and self-regulation might be accommodated within a process-product framework. A second strand of research might focus on investigating how the appraisal process occurs. This issue was not one of the aims of the present study, but an understanding of appraisal as a process would be necessary to ensure a comprehensive knowledge about the phenomenon of motivation for learning.

\section{References}

Ainley, M. (2006). Connecting with learning: Motivation, affect and cognition in interest processes. Educational Psychology Review, 18, 391-405. https://doi.org/10.1007/s10648-006-9033-0

Anderman, E. M., Noar, S. M., Zimmerman, R. S., \& Donohew, L. (2004). The need for sensation as a prerequisite for motivation to engage in academic tasks. In P. R. Pintrich \& M. L. Maehr (Eds.), Advances in motivation and achievement, Volume 13, Motivating students, improving schools: The legacy of Carol Midgley (pp. 1-26). Boston, MA: Elsevier. https://doi.org/10.1016/S0749-7423(03)13001-4

Bandura, A. (1997). Self-efficacy: The exercise of control. New York, NY: W.H. Freeman and Co.

Braun, V., \& Clarke, V. (2006). Using thematic analysis in psychology. Qualitative Research in 
Psychology, 3, 77-101. https://doi.org/10.1191/1478088706qp063oa

Busch, H., Hofer, J., Chasiotis, A., \& Campos, D. (2013). The achievement flow motive as an element of the autotelic personality: Predicting educational attainment in three cultures. European Journal of Psychology of Education, 28, 239-254. https://doi.org/10.1007/s10212-012-0112-y

Cadigan, F., Yichun, W., \& Clifton, R. A. (2013). Mathematic achievement of Canadian private school students. Alberta Journal of Educational Research, 59, 662-673.

Creemers, B., \& Kyriakides, L. (2015). Process-product research: A cornerstone in educational effectiveness research. Journal of Classroom Interaction, 50, 107-119.

Culbertson, S. S., Fullagar, C. J., Simmons, M. J., \& Zhu, M. (2015). Contagious flow: Antecedents and consequences of optimal experience in the classroom. Journal of Management Education, 39, 319-349. https://doi.org/10.1177/1052562914545336

Ekahitanond, V. (2013). Promoting university students' critical thinking skills through peer feedback activity in an online discussion forum. Alberta Journal of Educational Research, 59, 247-265.

Grossnickle, E. (2016). Disentangling curiosity: Dimensionality, definitions, and distinctions from interest in educational contexts. Educational Psychology Review, 28, 23-60. https://doi.org/10.1007/s10648-014-9294-y

Järvenoja, H., Järvelä, S., \& Malmberg, J. (2017). Supporting groups' emotion and motivation regulation during collaborative learning. Learning and Instruction, Advance online publication. https://doi.org/10.1016/j.learninstruc.2017.11.004

Kim, T., \& Schallert, D. L. (2014). Mediating effects of teacher enthusiasm and peer enthusiasm on students' interest in the college classroom. Contemporary Educational Psychology, 39, 134-144. https://doi.org/10.1016/j.cedpsych.2014.03.002

Landrum, B., \& Garza, G. (2016). What's in a name? Exploring the impact of naming assignments. Alberta Journal of Educational Research, 62, 306-317.

Linnenbrink, E. A., \& Pintrich, P. R. (2002). Achievement goal theory and affect: An asymmetrical bidirectional model. Educational Psychologist, 37, 69-78. https://doi.org/10.1207/S15326985EP3702_2

Litman, J. A. (2005). Curiosity and the pleasures of learning: Wanting and liking new $\begin{array}{lllll}\text { information. Cognition } & \text { and } & \text { Emotion, } & \text { 19, }\end{array}$ https://doi.org/10.1080/02699930541000101

Long, T., \& Johnson, M. (2000). Rigour, reliability and validity in qualitative research. Clinical Effectiveness in Nursing, 4, 30-37. https://doi.org/10.1054/cein.2000.0106

Loukomies, A., Juuti, K., \& Lavonen, J. (2015). Investigating situational interest in primary science lessons. International Journal of Science Education, 37, 3015-3037. https://doi.org/10.1080/09500693.2015.1119909 
Malmberg, L.-E., Pakarinen, E., Vasalampi, K., \& Nurmi, J.-E. (2015). Students' school performance, task-focus, and situation-specific motivation. Learning and Instruction, 39, 158-167. https://doi.org/10.1016/j.learninstruc.2015.05.005

Menna-Barreto, L., \& Wey, D. (2008). Time constraints in the school environment: What does a sleepy student tell us? Mind, Brain, and Education, 2, 24-28. https://doi.org/10.1111/j.1751-228X.2008.00025.x

Miele, D. B., \& Scholer, A. A. (2018). The role of metamotivational monitoring in motivation regulation. Educational Psychologist, 53, 1-21. https://doi.org/10.1080/00461520.2017.1371601

Op 't Eynde, P., \& Turner, J. E. (2006). Focusing on the complexity of emotion issues in academic learning: A dynamical component systems approach. Educational Psychology Review, 18, 361-376. https://doi.org/10.1007/s10648-006-9031-2

Ortony, A., \& Turner, T. J. (1990). What's basic about basic emotions? Psychological Review, 97, 315-331. https://doi.org/10.1037//0033-295X.97.3.315

Patrick, H., Ryan, A. M., \& Kaplan, A. (2007). Early adolescents' perceptions of the classroom social environment, motivational beliefs, and engagement. Journal of Educational Psychology, 99, 83-98. https://doi.org/10.1037/0022-0663.99.1.83

Pintrich, P. R. (2003). A motivational science perspective on the role of student motivation in learning and teaching contexts. Journal of Educational Psychology, 95, 667-686. https://doi.org/10.1037/0022-0663.95.4.667

Renninger, K. A., \& Hidi, S. (2016). The power of interest for motivation and engagement. New York, NY: Routledge. https://doi.org/10.4324/9781315771045

Renninger, K. A., Ewen, L., \& Lasher, A. K. (2002). Individual interest as context in expository text and mathematical word problems. Learning and Instruction, 12, 467-491. https://doi.org/10.1016/S0959-4752(01)00012-3

Rotgans, J. I., \& Schmidt, H. K. (2017). Interest development: Arousing situational interest affects the growth trajectory of individual interest. Contemporary Educational Psychology, 49, 175-184. https://doi.org/10.1016/j.cedpsych.2017.02.003

Ryan, R. M., \& Deci, E. L. (2000). Intrinsic and extrinsic motivations: Classic definitions and new directions. Contemporary Educational Psychology, 25, 54-67. https://doi.org/10.1006/ceps.1999.1020

Schiefele, U. (1999). Interest and learning from text. Scientific Studies of Reading, 3, 257-279. https://doi.org/10.1207/s1532799xssr0303_4

Schunk, D. H. (2004). Learning theories: An educational perspective. Upper Saddle River, NJ: Pearson Prentice Hall.

Silvia, P. J., Henson, R. A., \& Templin, J. L. (2009). Are the sources of interest the same for everyone? Using multilevel mixture models to explore individual differences in appraisal $\begin{array}{llll}\text { structures. } \quad \text { Cognition } \quad \text { and } & \text { 1389-1406. }\end{array}$ 
https://doi.org/10.1080/02699930902850528

Snyder, K. E., \& Linnenbrink-Garcia, L. (2013). A developmental, person-centered approach to exploring multiple motivational pathways in gifted underachievement. Educational Psychologist, 48, 209-228. https://doi.org/10.1080/00461520.2013.835597

Tanaka, A., \& Murayama, K. (2014). Within-person analyses of situational interest and boredom: Interactions between task-specific perceptions and achievement goals. Journal of Educational Psychology, 106, 1122-1134. https://doi.org/10.1037/a0036659

Tsai, Y.-M., Kunter, M., Lüdtke, O., Trautwein, U., \& Ryan, R. M. (2008). What makes lessons interesting? The role of situational factors and individual factors in three school subjects. Journal of Educational Psychology, 100, 460-472. https://doi.org/10.1037/0022-0663.100.2.460

Turner, J. C., \& Patrick, H. (2008). How does motivation develop and why does it change? Reframing motivation research. Educational Psychologist, 43, 119-131. https://doi.org/10.1080/00461520802178441

Vollmeyer, R., \& Rheinberg, F. (2006). Motivational effects on self-regulated learning with different tasks. Educational Psychology Review, 18, 239-253. https://doi.org/10.1007/s10648-006-9017-0

Wigfield, A., \& Eccles, J. S. (2000). Expectancy-value theory of achievement motivation. Contemporary Educational Psychology, 25, 68-81. https://doi.org/10.1006/ceps.1999.1015

Winne, P. H., \& Marx, R. W. (1989). A cognitive-processing analysis of motivation within classroom tasks. In C. Ames \& R. Ames (Eds.), Research on Motivation in Education, Volume 3, Goals and Cognitions (pp. 223-257). San Diego, CA: Academic Press.

Wolters, C. A. (2003). Regulation of motivation: Evaluating an underemphasized aspect of self-regulated learning. Educational Psychologist, $38, \quad$ 189-205. https://doi.org/10.1207/S15326985EP3804_1

Yanguas, Í. (2011). The dynamic nature of motivation during the task: Can it be captured? Innovation in Language Learning and Teaching, 5, 35-61. https://doi.org/10.1080/17501229.2010.519771

Zusho, A. (2017). Toward an integrated model of student learning in the college classroom. Educational Psychology Review, 29, 301-324. https://doi.org/10.1007/s10648-017-9408-4

\section{Copyright Disclaimer}

Copyright for this article is retained by the author(s), with first publication rights granted to the journal.

This is an open-access article distributed under the terms and conditions of the Creative Commons Attribution license (http://creativecommons.org/licenses/by/3.0/). 